\title{
CURSINHO PRÉ-VESTIBULAR DO IBILCE: OPORTUNIDADE DE INGRESSO AO ENSINO SUPERIOR
}

Luciana Aparecida Nogueira da Cruz, Ricardo Scucuglia Rodrigues da Silva, Joseane Gabriel Rodrigues, Ranieri Aparecido Romanini, Hugo Rocha Nhoato, Lucas Ramos Pereira, Natália Pinheiro.

Universidade Estadual Paulista - UNESP, Instituto de Biociências, Letras e Ciências Exatas, Departamento de Educação, São José do Rio Preto, SP. E-mail: lucruz@ibilce.unesp.br

Agência de fomento: Pró-Reitoria de Extensão da UNESP - PROEX

\section{RESUMO}

O ensino público no Brasil ainda não tem a qualidade necessária para que alunos oriundos desse segmento concorram igualitariamente em exames vestibulares para ingressarem no ensino superior público e de qualidade. Apesar dessa condição, intensifica-se a cada ano entre a população socioeconomicamente desfavorecida a demanda por cursar o ensino superior. Em razão dessa demanda, o Ibilce/UNESP oferece mais de 300 vagas/ano para curso pré-vestibular. 0 projeto de extensão Cursinho pré-vestibular do Ibilce/UNESP oferece gratuitamente às pessoas da comunidade, que desejam concorrer aos exames vestibulares e não possuem o conhecimento necessário para concorrer de forma igualitária com os demais vestibulandos, ensino de qualidade. O projeto, além de contribuir para a melhoria da qualidade do ensino dos pré-vestibulandos, também auxilia na formação pessoal e profissional de alunos da graduação e pós-graduação do Ibilce ao coordenarem e ministrarem aulas no cursinho.

Palavras-chave: cursinho pré-vestibular; ação extensionista; formação de professores; extensão universitária; ensino público.

\section{UNIVERSITY PREP COURSE IBILCE: OPPORTUNITY TO GET HIGHER EDUCATION}

\begin{abstract}
Public education in Brazil still does not have the quality required for students coming from this segment to compete equally entrance exams for enrolling in qualified higher education. Despite this condition, it intensifies every year, among socioeconomically disadvantaged population, the demand for higher education. Because of this demand, IBILCE/UNESP offers over 300 positions/year in a university prep course. The extension (or knowledge mobilization) project of the university prep course IBILCE/UNESP offers quality education, free of charge, to people in the community who wish to compete for entrance university exams and do not have the knowledge to compete equally with other pre-university school students. The project, beyond contributing to improving the quality of education of pre-university students, also assists in the personal and professional training of graduate and undergraduate students of IBILCE, whose coordinate and teach classes in the prep university course.
\end{abstract}

Keywords: university prep course; knowledge mobilization action; teacher education; university extension; public education. 


\section{INTRODUÇÃO}

Mesmo com a "quase universalização do acesso às séries iniciais que ocorreram em 1998 à educação básica, é visível o fato de que o ensino público fundamental e médio no Brasil ainda não tem a qualidade almejada por todos, o sistema público de ensino não oferece igualdade de oportunidades em comparação aos estudantes das escolas particulares" (FRANÇA e GONÇALVES, 2012, p. 305). Como consequência, os alunos oriundos deste segmento concluem o Ensino Médio apresentando muitas deficiências educacionais, impossibilitando-os, assim, de ingressarem em uma Universidade pública de qualidade, pois muitas das vagas são muito concorridas por meio dos exames vestibulares. Por essa razão, um grupo de estudantes universitários preocupados com a injusta concorrência nos exames vestibulares das universidades públicas entre egressos do ensino público e privado deu início ao Cursinho do Ibilce/UNESP em 1994.

O grupo, composto de estudantes de cursos de graduação e pós-graduação do Instituto de Biociências, Letras e Ciências Exatas da Universidade Estadual Paulista "Júlio de Mesquita Filho" Ibilce/UNESP, recebeu o apoio necessário da Direção e Vice direção do Instituto para realizar as atividades. Portanto, há mais de duas décadas o Ibilce tem a tradição de contribuir para o ingresso de estudantes oriundos da rede pública de ensino básico no ensino superior ou técnico. Certamente sem essa contribuição de um cursinho popular, muitos deles dificilmente almejariam chegar a uma Universidade (SANTOS, 2008).

Segundo o Censo Escolar de 2012, a rede estadual continua sendo a maior responsável pela oferta de Ensino Médio, dos 6,9 milhões de estudantes matriculados no Ensino Médio, 85\% estão em escolas públicas. A rede privada atende $12,7 \%$ e as redes federal e municipal atendem, juntas, pouco mais que $2 \%$ dos estudantes que estão no Ensino Médio (BRASÍLIA, 2013). Apesar dessa condição, intensifica-se a cada ano entre a população socioeconomicamente desfavorecida a demanda por cursar o ensino superior. Em razão dessa demanda os cursos pré-vestibulares populares (PVP), ou também chamados de comunitários, surgem num contexto contraditório do sistema educacional, com profundas desigualdades no que diz respeito ao acesso ao ensino superior, observa-se um aumento considerável na demanda pelo ensino superior e uma maior desproporção na relação candidato/vaga nos últimos anos, fenômeno que intensificou a competição por um lugar na Universidade e, ao mesmo tempo, a inflação dos diplomas (ZAGO, 2008).

Em 2003 o cursinho, seguindo a ideia já em curso da política de implementação de cursinhos voluntários e comunitários em toda a UNESP como projetos de extensão, recebeu o título de Cursinho pré-vestibular VestJr. Em 2007 alunos de cursos de licenciaturas do Ibilce/UNESP começaram um trabalho voluntário de "reforço escolar" em uma escola pública de São José do Rio Preto e notaram que a demanda era de um curso que abrangesse todas as disciplinas do ensino médio. Com o apoio da Direção da escola e aprovação da Pró-Reitoria de Extensão da UNESP - PROEX como projeto de extensão surgiu mais um cursinho, o Vitoriano. Desde então vem realizando suas atividades em escolas públicas, em 2016 passou a executar suas atividades na Faculdade de Tecnologia - FATEC de São José do Rio Preto. Em função da crescente demanda, em 2008 foi criado o projeto intitulado Cursinho Metamorfose para atender mais pessoas da comunidade. Tanto o VestJr quanto o Metamorfose realizam suas atividades diariamente no câmpus do Ibilce, o que possibilita uma aproximação dos cursistas ao ambiente Universitário. As três equipes VestJr, Vitoriano e Metamorfose compõem o projeto de extensão Cursinho do Ibilce/UNESP.

As atividades do VestJr e do Metamorfose acontecem no período noturno (das $19 \mathrm{~h}$ às $22 \mathrm{~h} 50 \mathrm{~m}$ ) no Ibilce. São quatro salas de aula com equipamento multimídia destinadas ao Cursinho, e uma sala para os coordenadores discentes, além de uma sala para depósito. Na FATEC, as aulas do Vitoriano acontecem no período vespertino, em duas salas de aula com recursos audiovisuais da própria FATEC. 
As atividades desenvolvidas pelas três equipes do Cursinho do Ibilce são voltadas para a preparação dos cursistas aos maiores vestibulares do Brasil. São ministradas aulas das disciplinas de Matemática, Física, Química, Biologia, História, Geografia, Filosofia, Sociologia, Língua Portuguesa (Literatura, Gramática e Redação), Inglês e Espanhol. As aulas acontecem de segunda a sexta-feira, nos períodos vespertino e noturno, e aos sábados, no período da tarde.

Vale ressaltar o importante papel formador que o cursinho proporciona aos discentes dos cursos de graduação e pós-graduação do Ibilce que atuam como bolsistas ou voluntários, coordenando e/ou ministrando aulas, pois essa experiência prática contribui positivamente para seu futuro profissional.

O projeto Cursinho pré-vestibular do Ibilce/UNESP contempla ações de caráter educativo e formativo que promovem a participação social e o desenvolvimento local. Tem como objetivos: a) promover o acesso de pessoas socioeconomicamente desfavorecidas ao ensino superior oferecendo um curso preparatório para o vestibular; b) contribuir para a formação de alunos de cursos de graduação e pós-graduação que atuam como coordenadores e lecionam no cursinho; c) articular ensino, pesquisa e extensão, promovendo diversas atividades embasadas nestes três pilares.

\section{MÉTODO}

Compõem a equipe do Cursinho Pré-Vestibular do Ibilce/UNESP o total de 90 pessoas, (alunos de graduação, pós-graduação e professores voluntários da rede pública e privada de ensino), dos quais 17 atuam na coordenação com atividades específicas e dois coordenadores docentes que são professores doutores do Departamento de Educação do Ibilce/UNESP.

Para que o cursinho aconteça são necessárias três etapas: 1) organização do processo seletivo de estudantes do Ibilce e de professores da rede de ensino que se voluntariam para compor o quadro da equipe que desenvolve as atividades de ensino; 2) organização do processo seletivo dos candidatos às vagas do cursinho; 3 ) desenvolvimento das atividades do cursinho durante o ano letivo.

\section{Processo seletivo da equipe que desenvolve as atividades de ensino no cursinho}

A equipe que coordena, ministra aulas e desenvolve as demais atividades do cursinho é composta por alunos de graduação e pós-graduação de diferentes cursos do Instituto, além de professores de escolas públicas ou privadas que atuam como voluntários.

Aqueles que desejam fazer parte da equipe do Cursinho passam por um processo seletivo que consta de aula teste sobre um tema pré-definido relacionado às disciplinas que ministrarão. $\mathrm{E}$ ainda, essa aula é avaliada por uma banca composta por membros da equipe do Cursinho e por alguns alunos do corrente ano. Os critérios de avaliação são: o domínio do conteúdo, o recorte temático, o domínio de estratégias didáticas em sala e a interação com os presentes. Dessa forma, os aprovados assumem as disciplinas pelas quais serão responsáveis durante todo o ano letivo, caso necessitem interromper suas atividades durante o ano, serão substituídos por outros candidatos que também foram aprovados no processo seletivo e encontram-se em lista de espera.

\section{PROCESSO SELETIVO DOS CANDIDATOS AO CURSINHO}

Até 2015, o projeto oferecia 300 vagas, que eram concorridas por cerca de 1.800 candidatos que se inscrevem todos os anos via internet. Em função da elevada demanda que aumenta a cada ano, tornou-se necessário criar um processo de seleção.

Os candidatos ao Cursinho se inscrevem via internet em um dos sites: http://www.cursinhometamorfose.com.br/portal/; http://www.cursinhovitoriano.com/cv/index; http://cursinhovestjr.com.br/ e passam por duas etapas de seleção: a) a primeira consiste em uma prova de conhecimentos gerais (50 questões de múltipla escolha envolvendo as áreas de: Língua 
Portuguesa, Matemática, Geografia, História, Física, Química, Biologia, Língua Inglesa, Filosofia) e redação que seleciona cerca de $40 \%$ dos candidatos; b) estes passam por uma entrevista (segunda etapa) que leva em conta as condições do candidato enquanto estudante da rede pública (exceção aos bolsistas de escolas privadas) e sua situação socioeconômica.

Após a seleção dos primeiros classificados e preenchimento das vagas oferecidas, permanece uma relação daqueles que não foram contemplados na primeira chamada, mas que poderão preencher as vagas que surgirem em caso de desistências no decorrer do ano.

Todo o processo seletivo é organizado e executado pelos coordenadores discentes do Ibilce/UNESP e voluntários que compõem a equipe do Cursinho.

\section{PÚBLICO ATENDIDO}

Alunos de escola pública ou que foram bolsistas no sistema de ensino privado. Quanto à situação socioeconômica, a renda familiar média das famílias dos candidatos varia entre $\mathrm{R} \$ 781,00$ e $\mathrm{R} \$ 1.300,00$ mensais.

Várias cidades da região são beneficiadas com a existência do Cursinho do Ibilce, tais como: Mirassol, Monte Aprazível, Onda Verde, Nova Granada, Icém, Paulo de Faria, Neves Paulista, Cedral, Uchoa, Bálsamo, Bady Bassitt, Potirendaba, José Bonifácio, Tanabi, Urupês, Ibirá, Palestina, Guapiaçu, entre outras; até mesmo do estado de Minas Gerais, como Fronteira, Frutal e Itapagipe.

\section{ATIVIDADES DESENVOLVIDAS PELA EQUIPE DO CURSINHO}

Dentre as inúmeras atividades, que os coordenadores discentes realizam, destacam-se: a coordenação de reuniões pedagógicas; a organização dos processos seletivos tanto dos que ministrarão aulas, como também dos candidatos que desejam frequentar o cursinho; a organização do quadro de disciplinas e horários das aulas; o controle da frequência dos alunos cursistas e a coleta de informações referente as aprovações nos exames vestibulares.

Os coordenadores discentes também têm contato direto com a Vice direção e com os coordenadores docentes, além de participarem de reuniões com a Pró-Reitoria de Extensão.

Outras atividades também são realizadas como a) formação para os membros da equipe que ministram aulas no cursinho; b) aulas expositivas e dialogadas sobre conteúdos específicos dos vestibulares das principais Universidades públicas do país: são ministradas as frentes de Gramática, Literatura, Matemática (Álgebra, Matemática Aplicada e Geometria), Física (Mecânica, Eletromagnetismo e Óptica/Termodinâmica), Química (Geral, Físico-Química e Orgânica), Biologia (Celular, Ecologia/Botânica e Zoologia), Geografia, História Geral e do Brasil, Filosofia, Inglês, Redação, Sociologia e Atualidades; c) monitorias de todas as disciplinas; d) consultas e acesso dos cursistas ao acervo da biblioteca do Ibilce/UNESP; e) simulados; f) aulas de reposição; g) oficinas de redação; h) excursões didáticas; i) promoção de atividades de cunho esportivo, cultural e científico-acadêmicas; j) atividades extraclasse: os alunos são convidados a participarem de palestras e/ou grupos de discussões temáticas na Universidade; k) confraternização de finalização do ano; l) cabe ressaltar que os alunos dos cursinhos são convidados a participar de projetos de extensão como o Coral, Oficina e Teatro de bonecos, entre outros.

\section{RESULTADOS OBTIDOS NA ATUAÇÃO DO CURSINHO}

Em duas décadas de existência os cursinhos pré-vestibular do Ibilce alcançaram excelentes resultados. Além da expressiva contribuição para o ingresso de pessoas economicamente desfavorecidas no ensino superior, esse projeto também já contribuiu para a formação de centenas de professores e pesquisadores. É notório que a experiência do Cursinho contribui tanto profissionalmente, quanto na realização pessoal dos estudantes, professores, voluntários e demais colaboradores. É interessante notar que muitos deles foram alunos de 
cursinhos desse tipo. Isso significa que a participação em um projeto desta magnitude desenvolve valores e sentimentos morais, tais como gratidão, solidariedade, respeito mútuo, entre outros. Observa-se entre os membros da equipe do cursinho o desejo de proporcionar a outros jovens, como contrapartida do que thes foi oferecido, oportunidades de estudo e de ingresso no ensino superior.

\section{NÚMERO DE EGRESSOS DO CURSINHO QUE FORAM APROVADOS EM VESTIBULARES OU CONCURSOS}

Os dados levantados dos três cursinhos foram a partir das tabelas enviadas para a PróReitoria de Extensão da UNESP (PROEX), ressaltando que, nem sempre se obteve sucesso em entrar em contato com todos os alunos, assim considerando um erro de $2 \%$ a $3 \%$ para mais nas aprovações ou não aprovações para os anos de 2014 e 2015.

A tabela a seguir representa as aprovações de alunos dos cursinhos das três equipes (Metamorfose VestJr e Vitoriano).

Tabela 01. Aprovações dos alunos do Cursinho do Ibilce

\begin{tabular}{|l|l|l|l|}
\hline Distribuições/Ano & $\mathbf{2 0 1 2}$ & $\mathbf{2 0 1 3}$ & $\mathbf{2 0 1 4}$ \\
\hline UNESP & $13 \%$ & $27 \%$ & $24 \%$ \\
\hline Outras Estaduais & $29 \%$ & $41 \%$ & $38 \%$ \\
\hline Prouni & $19 \%$ & $25 \%$ & $27 \%$ \\
\hline Outros & $5 \%$ & $3 \%$ & $4 \%$ \\
\hline Não Aprovados & $6 \%$ & $2 \%$ & $4 \%$ \\
\hline
\end{tabular}

*Outras Estaduais - UNICAMP, USP, UNIFESP, SISU *Prouni-Bolsas de 100\% e 50\% *Outros - Concursos, aprovações em medicina na Argentina, Bolsa no Programa Escola da família e colégios militares.

Obs.: Nas aprovações de 2013, a diferença vista na somatória ocorre por muitos alunos não retornarem contato.

Cabe aqui acrescentar que esta experiência vem gerando produtos científico-acadêmicos, tais como trabalhos de conclusão de curso (ALVARES, 2015), apresentações de comunicação e publicações de artigos em eventos científicos; trabalhos apresentados e publicados no 8 응 Congresso de Extensão Universitária da UNESP (RODRIGUES et al., 2015).

Anualmente a divulgação do cursinho é realizada em mídias eletrônicas, televisivas e impressas (jornais, telejornais, rádios, redes sociais e páginas da web), o que dá visibilidade para a sociedade da atuação social que a UNESP vem desenvolvendo tão seriamente.

\section{RESULTADOS ESPERADOS}

Embasados nas experiências conquistadas até o momento, espera-se que pelo menos $70 \%$ dos alunos matriculados terminem o curso e destes, cerca de $50 \%$ sejam aprovados em vestibulares de instituições de ensino superior públicas ou privadas. Tais expectativas derivam dos resultados alcançados nos anos anteriores.

O Cursinho Pré-vestibular do Ibilce espera proporcionar ensino de excelente nível e de forma gratuita para pessoas da comunidade que não têm condições financeiras de pagar um cursinho particular. Estima-se que essas pessoas possam dar continuidade a um projeto de formação universitária e construir uma sociedade na qual os próprios cidadãos possam colaborar para o desenvolvimento de sua comunidade. Além disso, objetiva-se dar oportunidade aos alunos de graduação e pós-graduação de participarem do Cursinho ministrando aulas, adquirindo, assim, experiência docente e construindo valores morais como generosidade e solidariedade, durante a própria graduação (ou pós-graduação).

Pretende-se estimular os alunos a enveredarem por pesquisas que contemplem a ação do cursinho (TCCs, projetos de Iniciação Científica, apresentação de comunicações em eventos 
científicos, publicação de artigos) assim como a participação em eventos promovidos pela própria UNESP (Congressos de Extensão, por exemplo)

\section{CONCLUSÃO}

O Cursinho pré-vestibular do Ibilce/UNESP há mais de duas décadas presta um serviço de excelente qualidade aos estudantes socioeconomicamente desfavorecidos. Estes, certamente têm no Cursinho gratuito a única chance de concorrerem aos exames vestibulares de forma justa e igualitária com pessoas que cursam cursinhos privados. Portanto, o apoio da Pró-Reitoria de Extensão Universitária da UNESP é fundamental para garantirmos a continuidade desse trabalho tão valoroso para a sociedade. Pelas razões aqui elencadas, são solicitadas 20 bolsas que serão destinadas aos estudantes de graduação que coordenam o cursinho com seriedade, responsabilidade e muita dedicação.

\section{AGRADECIMENTOS}

À Fundação de Apoio à Pesquisa e Extensão de Rio Preto - FAPERP, que em 2013 contribuiu com uma verba revertida para suprir os gastos com xerox e uniformes (camisetas) para os membros da equipe do Cursinho. Ao Cursinho Alternativo (http://www.cursinhoalternativo.com.br/), que desde 2015 é nosso principal parceiro. À PROEX/UNESP pelas bolsas concedidas aos coordenadores discentes. Ao Ibilce e à FATEC que disponibilizam a infraestrutura necessária para que as atividades do cursinho sejam realizadas.

\section{REFERÊNCIAS}

ALVARES, Jackson Américo. A contribuição da prática docente nos Cursinhos pré-vestibulares na formação de professores de Física. 2015. Trabalho de conclusão de Curso em Licenciatura em Física. Universidade Estadual Paulista. São José do Rio Preto. 2015

BRASÍLIA. Instituto Nacional de Estudos e Pesquisas Educacionais Anísio Teixeira. Censo da educação básica: 2012 - resumo técnico. Brasília: Instituto Nacional de Estudos e Pesquisas Educacionais Anísio Teixeira, 2013.

FRANÇA, M.T.A. e GONÇALVES, F.O. Sistemas públicos de ensino fundamental e a perpetuação da desigualdade: democracia e qualidade educacional como promotoras de justiça social. R. Bras. Est. Pop., Rio de Janeiro, v. 29, n. 2, p. 303-322, 2012

RODRIGUES, Joseane Gabriel, et. al. Perfil dos interessados no cursinho metamorfose do IBILCE. Anais do 8o Congresso de Extensão Universitária da UNESP. 2015.

SANTOS, R.E. Pré-vestibulares populares: dilemas políticos e desafios pedagógicos. In: (org.) CARVALHO, J. C. B.; ALVIM FILHO, H.; COSTA, R. P. Cursos pré-vestibulares comunitários: espaços de mediações pedagógicas. Rio de Janeiro: Ed. PUC-Rio, 2008.

ZAGO, Nadir. Cursos pré-vestibulares populares: limites e perspectivas Perspectiva, Florianópolis, v. 26, n. 1, 149-174, jan./jun. 2008. 